\title{
¿Qué memoria(s) para Buenos Aires? \\ Un análisis comparativo de los casos del Santuario de Cromañón y del Espacio para la Memoria y para la Promoción y Defensa de los Derechos Humanos
}

\author{
Cecilia Palacios* \\ Anabella Rodríguez**
}

La ciudad de Buenos Aires se encuentra cubierta por múltiples marcas territoriales (monumentos, memoriales, altares populares, etc.) que rememoran hechos conflictivos y procesos político-sociales de la historia reciente y que encarnan los diversos recuerdos de sus ciudadanos. A partir de los casos emblemáticos del Espacio para la Memoria (ex ESMA) y del Santuario de Cromañón nos preguntamos cómo se insertan estos lugares de recuerdo en el entramado de la ciudad, en emplazamientos y funcionamientos bastante disimiles que, no obstante, los ubican como iconos del recuerdo y la conmemoración. Nos interesa cuestionar sobre los diversos modos en que puede territorializarse e incluso institucionalizarse la memoria en determinado espacio.

Palabras clave: lugares de memoria, Santuario de Cromañón, espacio para la memoria, institucionalización de la memoria.

Fecha de recepción: 15 de junio de 2011.

Fecha de aceptación: 16 de mayo de 2012.

What Memories for Buenos Aires? A Comparative Analysis of the Cases of the Cro-Magnon Sanctuary and the Space for Memory and the Promotion and Defense of Human Rights

The city of Buenos Aires is covered with several territorial markers (monuments, memorials, popular altars, etc.) recalling conflictive events and political-social processes in recent history that embody the various memories of its citizens. On the basis of emblematic cases in the Space for Memory (ex ESMA) and the Cro-Magnon Sanctuary, we explored how these places of memory are inserted in the city's structure, in quite dissimilar locations and functions that nevertheless identify them as icons of memory and commemoration. We explore the different ways in which memory can be territorialized and even institutionalized in a specific space.

Key words: places of memory, Cro-Magnon Sanctuary, space for memory, institutionalization of memory.

* Universidad de Buenos Aires / Conicet. Correo electrónico: <ceciliapalacios@ gmail.com>.

** Universidad de Buenos Aires. Correo electrónico: <anabellarz@gmail.com>.

ESTUDIOS DEMOGRÁFICOS Y URBANOS, VOL. 28, NÚM. 2 (83), 2013, 323-341 


\section{Introducción}

El 24 de marzo de 1976, con un golpe de Estado a manos de las Fuerzas Armadas, se inauguró en Argentina un nuevo periodo dictatorial que sería el más sangriento y triste de la historia nacional. El balance más oscuro de esta época de terror y muerte se cuenta en miles y miles de torturas, secuestros y más de 30000 personas aún hoy desaparecidas. Los centros clandestinos de detención, tortura y exterminio (CCDTyE, en adelante) se contaban también por miles en todo el territorio nacional. Uno de los más grandes funcionó en lo que otrora fuera la Escuela de Mecánica de la Armada (ESMA), en la ciudad de Buenos Aires, por donde estuvieron detenidas más de 5000 personas, la gran mayoría de las cuales continúa aún hoy desaparecida. Actualmente dicho lugar encarna, por un lado, el horror de haber funcionado como CCDTyE, a la vez que se erige como símbolo de una nueva "cultura de los derechos humanos", tras la recuperación del predio de manos militares, en el año 2004, y su nueva denominación: "Espacio para la Memoria y para la Promoción y Defensa de los Derechos Humanos" (en adelante Espacio para la Memoria). Desde el año 2007 se ofrecen visitas guiadas por dicho espacio, a las que se puede acceder libre y gratuitamente previa solicitud.

Veintiocho años después del golpe, el 30 de diciembre de 2004, una bengala -que arrojó el propio público del lugar-desató un incendio en el microestadio de rock República de Cromañón, a media cuadra de Plaza Miserere en el barrio porteño de Once. El incendio -empeorado por la clausura de las puertas de emergencia- terminó con 194 muertos, en su mayoría jóvenes de entre 14 y 25 años. Al día siguiente los familiares y los vecinos de la zona se acercaron hasta el lugar en donde habían yacido los cuerpos muertos de los asistentes -vallado ahora por cercas policiales en la intersección de las calles Bartolomé Mitre y Ecuador- y dejaron flores, estampitas, objetos personales de las víctimas, etc., e iniciaron así lo que luego se convertiría en el "Santuario de Cromañón", el cual -lejos de los planes de varios sectores sociales interesados en extirparlo- ha ido consolidándose hasta volverse una imagen estable de esta ciudad. A la par del memorial, el gobierno de la ciudad de Buenos Aires construyó en 2005, con la ayuda de un grupo de padres de Cromañón, la "Plaza de la Memoria", una especie de plaza temática que recuerda solemne y someramente a las víctimas, y que rivaliza con el Santuario en la forma de definir las legítimas maneras de recordar a las víctimas. 
A partir del análisis de estos dos casos emblemáticos de la ciudad, que encarnan los distintos y conflictivos recuerdos de sus ciudadanos, nos proponemos analizar e identificar de qué modo cada uno de estos lugares se inscribe en la trama urbana, de qué modo reivindica su estatuto de lugar de memoria y en qué medida los distintos recuerdos que cada uno contiene se ven territorializados en el espacio urbano a partir de proyectos de conmemoración y rememoración distintos. Como en Las ciudades invisibles, de Italo Calvino, intentaremos dar cuenta de las múltiples lecturas a las que pueden someterse las ciudades. En Zirma, una de las ciudades imaginarias del libro, todos los viajeros tienen un recuerdo claro de la ciudad, pero a la vez todos recuerdan cosas diferentes que para grabarse en la memoria se han repetido múltiples veces. O en Tamara, donde los objetos y lugares sólo adquieren sentido en relación con el signo que los define. La ciudad no tiene ningún significado si no está anclada en el relato sobre ella; es el texto el que define su sentido.

\section{La ciudad y sus lugares}

Como se dijo, el actual Espacio para la Memoria se encuentra emplazado en la ex ESMA, donde funcionó de 1976 a 1982 uno de los CCDTyE de mayor envergadura del país y, ciertamente, el más grande de la ciudad de Buenos Aires, en donde en diciembre de 2002 la legislatura local aprobó la ley número 961 por la que se creaba el Instituto Espacio para la Memoria. Dos años más tarde se formó un ente bijurisdiccional -donde tienen injerencia el Estado Nacional y el Gobierno de la Ciudad-y se creó el actual Espacio para la Memoria. A partir del año 2007 el predio fue totalmente recuperado del dominio militar y actualmente lo administran tanto el Estado (municipal y nacional) como diversos organismos de derechos humanos y sobrevivientes que gestionan su funcionamiento. Está ubicado sobre la Avenida del Libertador, en el barrio de Núñez, en una de las zonas más residenciales de Buenos Aires y se abrió al público desde el $1^{\circ}$ de octubre de 2007, incluyendo visitas guiadas (previamente pactadas, y de carácter obligatorio si se quiere recorrer el lugar) que duran aproximadamente dos horas. Cuando comenzó a gestarse la idea del traspaso y de la creación del Espacio para la Memoria, el destino que habría de darse al lugar fue objeto de múltiples propuestas, contrapropuestas y proyectos de diversa índole que fueron compitiendo por establecerse de modo 
medianamente definitivo. ${ }^{1}$ Aún está en discusión el destino del Espacio, pero hay en líneas generales un cierto consenso sobre su funcionamiento.

El Santuario de Cromañón está ubicado en la esquina de Bartolomé Mitre y Ecuador, en el barrio porteño de Once, a unos cuantos metros de donde se incendiara en 2004 el microestadio República de Cromañón durante el recital de la banda local Callejeros. Fue instaurado espontánea y progresivamente a horas del siniestro por los propios familiares de los jóvenes muertos y por los sobrevivientes del incendio, en memoria de quienes perdieron la vida allí. En el año 2005 el gobierno de la ciudad de Buenos Aires construyó al lado del Santuario Cromañón una plaza llamada Plaza de la Memoria en homenaje a los muertos del microestadio. Desde entonces tanto el Santuario como la Plaza de la Memoria se emplazan para conmemorar el mismo acontecimiento dentro de la trama urbana y se usan para las actividades del movimiento social que se originó a partir del incendio, conocido como Movimiento de Víctimas, Familiares y Adherentes por Cromañón. ${ }^{2}$

\section{La ciudad y sus memorias}

Así, tanto el Espacio de la Memoria como el Santuario de Cromañón (cada uno con sus particularidades) se presentan como lugares que rememoran dentro de la ciudad hechos conflictivos y procesos políticos y sociales de la historia reciente y que encarnan los diferentes recuerdos de sus ciudadanos. En este sentido es posible pensarlos como lugares de memoria en el sentido que los define Pierre Nora, es decir, topos o núcleos que condensan diferentes representaciones sobre la memoria; son, en definitiva, "una realidad completamente simbólica" (Nora, 1998: 19). Por ende, su estudio y análisis supone la tarea de "desentrañar su verdad simbólica más allá de su realidad histórica" (idem). En esta forma podemos considerar como lugares de memoria tanto a los monumentos, edificios o memoriales, como a los emblemas, aniversarios, divisas... En palabras del propio Nora: "la gama de objetos posibles es, de hecho, infinita" (op. cit.: 20), pues estos lugares constituyen núcleos significativos materiales o inmateriales en los cuales la memoria colectiva de un grupo se encarna para ser preservada y estabilizada.

1 Para ahondar sobre esta cuestión véase Palacios, 2010.

${ }^{2}$ De aquí en adelante Movimiento por Cromañón. 
El planteamiento de Nora, sin embargo, no se concentra en dar cuenta de las posibles pugnas por el sentido de esos lugares. Un lugar de memoria, desde nuestra perspectiva, es siempre un lugar de conflicto, un lugar en el que los recuerdos que encierra están permanentemente siendo disputados, puestos en cuestión, resignificados. Y esto es así por el propio carácter colectivo de la memoria, que hace de ella un objeto constante de luchas memoriales. Pensar en la memoria como sinónimo de tradición compartida o de consenso no puede dar cuenta de la politicidad que la habita, de cómo es que va construyéndose; es decir, cómo surge, de qué modo se sostiene en el tiempo, crea un discurso propio y lo legitima, y quiénes son los actores individuales y colectivos que intervienen en este proceso político de construcción memorial.

El planteamiento de Pollak (2006) lleva a pensar en estas cuestiones, pues adopta una perspectiva de análisis constructivista, por cuanto

ya no se trata de lidiar con los hechos sociales como cosas sino de analizar cómo los hechos sociales se hacen cosas, cómo y por quién son solidificados y dotados de duración y estabilidad. Aplicado a la memoria colectiva ese abordaje se interesará, por lo tanto, por los procesos y actores que intervienen en el trabajo de constitución y formalización de las memorias [Pollak, 2006: 18].

De modo complementario los trabajos de Elizabeth Jelin (2002, 2003 y 2004) dan cuenta de cómo ya no es posible hablar ya de una memoria sino de memorias, en tanto la pluralidad es en sí misma una característica esencial y constitutiva de la memoria. En este sentido, el concepto de "emprendedores de la memoria"3 que ella propone permite analizar la acción concreta de grupos o individuos que realizan determinadas prácticas sociales por las luchas del sentido del pasado. ${ }^{4}$ Así, es posible focalizar en "los actores sociales y políticos, en su ubicación en escenarios públicos, en sus confrontaciones y sus luchas, alianzas e identificaciones con otros actores" (Jelin, 2002: 7). Por otra parte lleva a "reconocer el carácter construido y cambiante de los sentidos del

3 "Toda decisión de construir un monumento, de habilitar lugares donde se cometieron afrentas graves a la dignidad humana (campos de concentración y detención, especialmente) como espacios de memoria [...] es fruto de la iniciativa y la lucha de grupos sociales que actúan como "emprendedores de la memoria”" (Jelin, 2002: 54-55).

${ }^{4} \mathrm{El}$ enfatizar en la conflictividad de las memorias no nos exime de aceptar que siempre existen también momentos de consenso y homogeneidad de éstas, sin los cuales sería imposible hablar de una dimensión colectiva y compartida de la memoria. 
pasado, de los silencios y olvidos históricos, así como el lugar que sociedades, ideologías, climas culturales y luchas políticas asignan a la memoria" (Jelin, 2004: 91). Desde esta óptica se abre un camino para comprender las formas en que se vuelven hegemónicas ciertas posturas, mientras que otras quedan ocultas o en segundo plano, pero pueden reactivarse en una u otra coyuntura histórica (en este sentido la propuesta es similar a la de Pollak cuando habla de "memorias subterráneas"). ${ }^{5}$

De este modo se torna posible entender a la memoria como un proceso social de producción de sentido (Verón, 1993 [1987]) que va construyéndose en el tiempo y cuyo funcionamiento supone la ruptura, la discontinuidad y lo heterogéneo. En consecuencia, nos interesa dar cuenta del "carácter sociocomunicativo de la construcción del pasado por medio de la memoria", pues "el pasado que la memoria reactualiza es una construcción social” (Ramos, 1989: 69).

\section{La visita al Espacio de la Memoria}

Quienquiera que desee realizar una visita a la ex ESMA, debe pactar con antelación el día y horario de la visita, que se encuentran prefijados de antemano (tres días a la semana, dos visitas por día, con un total de nueve guías que se alternan en el trabajo). Una vez en el lugar se forman contingentes de visitantes de entre 20 y 50 personas por visita. Las primeras explicaciones del guía refieren a la duración del recorrido (de aproximadamente dos horas) y a ciertas indicaciones (por ejemplo, cuándo es posible tomar fotos y cuándo y dónde no; cuál será la dinámica de la visita, qué lugares serán visitados, etc.). Lo primero que se dice es que la reconstrucción y la recuperación del ex CCDTyE han sido posibles gracias al testimonio de algunos sobrevivientes. Es decir, todas las descripciones, respuestas a consultas y reconstrucciones del lugar parten del testimonio como instrumento principal de recuperación del espacio.

La visita puede dividirse en dos momentos diferenciados: el primero es en los exteriores del predio, mientras que el segundo se lleva a cabo dentro del edificio del Casino de Oficiales. Cabe destacar que la visita emula el recorrido que hacían quienes llegaban a la ESMA ile-

5 “[...] una vez que las memorias subterráneas logran invadir el espacio público, reivindicaciones múltiples y difícilmente previsibles se acoplan a esa disputa de la memoria" (Pollak, 2006: 19-20). 
galmente detenidos. Durante el recorrido se encuentran numerosos carteles indicativos ("Por esta entrada, los represores ingresaban a los secuestrados, encapuchados y maniatados, en vehículos sin identificación o con identificación falsa...") y mapas del predio o de algunas de las instalaciones cuya fisonomía fue modificada.

Resulta interesante que si bien las visitas no son bilingües, sí en cambio las señales están escritas tanto en español como en inglés. Esto se explica, según los guías, porque una gran cantidad de extranjeros visita el lugar. ${ }^{6}$ Cuando se llega al Casino de Oficiales ya no está permitido tomar fotografías pues "el edificio es prueba material y judicial", según se indica. ${ }^{7} \mathrm{El}$ recorrido, como se dijo, emula al de un detenido: se comienza por el sótano (donde los detenidos, cuando llegaban, eran sometidos a tortura) y luego se asciende hasta llegar a los lugares conocidos como "Capucha" y "Capuchita", en los que permanecían detenidos quienes eran secuestrados. Se observan carteles y señalamientos dentro del Casino de Oficiales, así como diversos planos del lugar, al que cuando funcionaba como centro clandestino le fue modificada la fisonomía en sucesivas ocasiones, ya fuera para ampliar o reducir espacios o para lograr la aquiescencia de la famosa visita de inspección de la CIDH en 1979, lo que provocó ciertas reformas edilicias. "¿Cómo representar entonces los huecos, lo indecible, lo que ya no está?" (Jelin y Langland, 2003: 2) En "Capucha”, por ejemplo, los únicos carteles que se observan son de testimonios de sobrevivientes. Todo el edificio se ha vaciado completamente, pues se ha considerado que "representar el horror generaría parálisis". ${ }^{8}$ La visita concluye en el edificio al que se le denomina "Quincho", donde se da a los visitantes la posibilidad de firmar un libro de visitas, se les entrega folletería y se pueden sentar a descansar tras el extenso recorrido.

${ }^{6}$ En el momento de realizar este trabajo no nos fue posible conseguir una respuesta certera sobre la cantidad aproximada o el porcentaje de visitas extranjeras que llegan al lugar. Sin embargo en todas las visitas que hemos realizado ha habido más de tres extranjeros visitando el Espacio, y los guías afirmaron que su número va en aumento.

${ }^{7}$ Idéntica frase se repite en las sucesivas visitas, de ahí que no pueda atribuirse a un guía u otro en particular.

${ }^{8}$ Débora (guía), 7 de septiembre de 2009. 


\section{El caso Cromañón}

El Santuario por dentro

El Santuario está instalado en la intersección de las calles Mitre y Ecuador, cortando el tránsito por Mitre. Lo encabeza una consigna pintada en negro: "el santuario de nuestros ángeles del rock 30-12-04 nunca más cromañón”. Sobre el piso, o colgando del techo hay entre otras cosas, banderas con las caras de los muertos, fotos, cuadros, zapatillas, collares, palos para malabares de circo, rosarios, camisetas con logos de bandas de rock, velas, flores, santos, vírgenes, botellas vacías de cerveza, poemas, etc. También hay cruces de madera que parecen haberse improvisado en el lugar. Todo en el Santuario de Cromañón parece avejentado, tal vez por el humo de esa noche, pues muchos objetos se recuperaron tras el incendio, o por el paso del tiempo. Hay varias consignas escritas con marcador, entre ellas: "Ibarra asesino", ${ }^{9} \mathrm{o}$ el nombre de algún chico muerto en Cromañón seguido por "asesinado" o "masacrado". En el lugar "sobresalen" visualmente algunas fotos, ya sea por su tamaño o por la cantidad de ellas.

Quienes hacen uso del Santuario durante las marchas por el aniversario del siniestro y durante las marchas mensuales de cada día 30 son en su mayoría jóvenes de entre 14 y 21 años vestidos con zapatillas, sobre todo, de la marca Topper, ropa de batik, camisetas con símbolos de Los Rolling Stones, Los Redonditos de Ricota, Callejeros, etc. Frecuentemente el Santuario es el punto de salida o de llegada de dichas marchas. Entre semana suele haber muy pocos visitantes, pero aumentan los domingos, cuando la concurrencia también es mayoritariamente de jóvenes, aunque muchos parecen no tener lazos con los muertos, sino estar haciendo "simple turismo". La gente que se acerca toca las fotos, llora, se persigna frente al Santuario. Cuando en el lugar hay padres de las víctimas, éstos suelen ocupar el lugar en forma diferenciada y jerárquica, ya que son ellos quienes dan las órdenes y especifican los lugares en donde se realizarán las actividades.

\section{La Plaza de la Memoria}

Un cartel de metal sobre la puerta marca la entrada de la Plaza. Reza: "En memoria de los 194 ángeles masacrados en Cromañón seguimos

${ }^{9}$ Aníbal Ibarra, nombre del jefe de gobierno porteño destituido por juicio político a causa del incendio. 
pidiendo justicia y verdad para que descansen en la paz que se merecen", sobre un fondo celeste en el que se encuentran pintadas unas zapatillas marca Topper blancas colgando de los cordones. La Plaza es un espacio rectangular, como una caja de zapatos, cortada a lo largo por un camino de cemento; de él se desprenden caminos laterales que llevan hacia una enorme pared blanca que se sitúa a la derecha del que ingresa, en la cual están escritos en letras negras iguales los nombres de las víctimas fatales junto con sus fotos. La pared comienza con un cartel de grandes dimensiones, que reza: "A lo que el cielo no pudo esperar". Los nombres se ordenan en columnas y filas que se repiten regularmente, equidistantes entre sí, separadas por muros de unos $50 \mathrm{~cm}$ de alto, que también sirven como asientos. La Plaza de la Memoria es un espacio enteramente de cemento, del estilo de las plazas que se construyeron en otros lugares de Buenos Aires para recordar algún acontecimiento traumático, como el Parque de la Memoria en Costanera Sur o la Plaza Embajada de Israel. El lugar se ilumina con una serie de reflectores del lado izquierdo, y durante el día abunda la luz natural. En ella no hay carteles políticos ni grafitis o carteles de protesta, y tampoco hay zapatillas colgadas (símbolo típico del Santuario), pero en cambio abundan los osos de peluche, las cartas, las fotos, etc. Al final de la Plaza hay una réplica de La Piedad de Miguel Ángel (la Virgen con su hijo moribundo entre los brazos).

\section{Los lugares y las políticas de memoria}

Llegados a este punto podríamos preguntarnos qué tipo de consignas o propuestas en relación con la memoria guían a los lugares que hemos descrito. ¿Cuáles son las premisas bajo las cuales funcionan estos lugares? ¿Qué relaciones pueden entablarse entre los distintos proyectos de rememoración y conmemoración que dichos lugares encarnan?

El caso de la transformación de la ex ESMA en Espacio para la Memoria es un claro ejemplo de cómo el Estado (nacional, municipal) y diversas organizaciones deciden, promueven, avalan y ejecutan políticas de memoria. Para referirnos a estas políticas tomamos a grandes rasgos la definición de Rabotnikof:

Con políticas de la memoria nos referimos estrictamente [...] a las formas de gestionar o de lidiar con ese pasado, a través de procedimientos de $a$ ) justicia retroactiva, $b$ ) instauración de conmemoraciones, de fechas y lu- 
gares, c) apropiaciones simbólicas de distinto tipo. Pero también con el término políticas de la memoria debería hacerse referencia a las "grandes ofertas de sentido temporal”, o a las narrativas más generales que ofrecen interpretaciones globales sobre ese pasado dentro de ciertos marcos institucionales [Rabotnikof, 2007: 14].

Así, el Espacio para la Memoria ha sido concebido para funcionar como "centro de debate social, cultural y político y de transmisión de la memoria y la promoción de los derechos humanos", según se desprende de su documento fundacional. ${ }^{10}$ En tanto espacio de articulación ${ }^{11}$ supuso la confrontación y negociación de múltiples proyectos de gestión que implicaron asimismo diversas concepciones respecto del lugar, sus usos institucionales, la producción social del espacio y su inserción en la trama urbana de la ciudad. Su forma de gestión, de administración y de funcionamiento ha sido previamente delineada y definida por políticas específicas orientadas según determinados objetivos. Es, acaso, el lugar de memoria más emblemático de Buenos Aires. Por poner un sencillo ejemplo: se invita a las delegaciones extranjeras que visitan el país a recorrer el Espacio junto con las autoridades que actualmente lo administran. ${ }^{12}$

El Santuario Cromañón constituye un lugar de memoria no institucional que ha sido convertido como tal a partir de las acciones concretas y sistemáticas de los padres y amigos de las víctimas, así como de sobrevivientes que cuentan con capacidad para definir e imponer tanto socialmente como en el interior del propio movimiento un recuerdo específico de los jóvenes muertos. Este recuerdo particular condensa y resalta virtudes de las víctimas como el heroísmo, el sacrificio y la inocencia, y deja de lado conductas potencialmente peligrosas como el uso de fuegos artificiales. La inscripción del Santuario en la trama urbana de Buenos Aires ha generado fuertes controversias sociales, ya que corta el tránsito por Bartolomé Mitre y obliga a 10 de las 30 líneas que circulan por la zona a cambiar su recorrido. En reiteradas ocasiones las sucesivas administraciones del gobierno local han expuesto la necesidad de abrir Mitre desmantelando el Santuario y privilegiando la Plaza de la Memoria, a lo cual se ha opuesto férreamente el

${ }^{10}<$ http://www.derhuman.jus.gov.ar/espacioparalamemoria>.

${ }^{11}$ Instituto Espacio para la Memoria, 2008, "Nuestra memoria", Memoria Anual 2008, Buenos Aires.

${ }^{12}$ Para ahondar en torno a las razones por las que este ex centro clandestino en particular se ha convertido en símbolo de la desaparición y los crímenes de la última dictadura véase Feld, 2008. 
Palacios y Rodríguez, ¿QUÉ MEMORIA(S) PARA BUENOS AIRES?

Movimiento de Familiares por Cromañón, no sin diferencias en su interior, arguyendo que allí quedaron los cuerpos de sus hijos muertos y que en dicha calle deben hacerse aún ciertas pericias judiciales, entre otras razones. ${ }^{13}$ Resultan curiosas ciertas similitudes con lo que ocurrió en su momento respecto de la posibilidad de organizar visitas guiadas a la ex ESMA, que para muchos de quienes plantearon algunas propuestas había sido su lugar de cautiverio y tortura, y la actual reticencia a tomar fotografías dentro del lugar con el argumento de que el edificio del Casino de Oficiales constituye una prueba material y judicial y que, por lo tanto, se debe preservar.

Cabe mencionar que el Espacio para la Memoria y el Santuario Cromañón fundan su razón de ser -y de permanecer- en el hecho de que ambos señalan con su sola presencia el espacio específico en el que sucedieron los hechos: tanto el Santuario como la ex ESMA marcan que allí, en ese espacio-tiempo de la ciudad, ocurrieron los crímenes y las muertes que han denunciado quienes rememoran estos hechos y recuerdan a estas víctimas, y establecen de este modo un anclaje indisoluble entre el territorio y la memoria. Esta territorialización de las distintas memorias se ancla a su vez en el problema de la corporalidad de la experiencia directa y en la cuestión del testimonio. Ambos lugares parecen decirnos: "estas víctimas realmente existieron, realmente pasaron por allí”. La necesidad de preservar el lugar en su materialidad, en los dos casos analizados, y con casi idénticos argumentos, nos conduce a pensar en la posibilidad de que exista un vínculo no sólo entre el espacio y la identidad, sino entre el espacio, la identidad y el recuerdo.

En términos de Ricoeur (2002), tanto el Espacio para la Memoria como el Santuario de Cromañón encarnarían una pretensión verista de la memoria que en sendos lugares se rememora, ya que atribuye a éste el ser la verdad de aquello que ya no es, pero que fue antes. Así, ambos lugares resultan receptáculos, territorializaciones de múltiples memorias, aunque con gradientes. La memoria que encarna el Espacio para la Memoria se encuentra allí, contenida entre las paredes del

13 Debemos consignar que en el proceso de corrección de este artículo, a raíz de un accidente ferroviario que costó la vida a 51 personas, ocurrido el 22 de febrero de 2012 en la estación del ferrocarril de Once, a unos cuantos metros del Santuario, se decidió abrir una arteria paralela a la calle Mitre para permitir de ahora en adelante el tránsito vehicular. Las razones para habilitar esta arteria paralela se explican porque el día del accidente de trenes se tornó difícil la entrada de ambulancias y vehículos de rescate hacia el interior de la estación ferroviaria. Para saber más sobre este tema véase <http://www. infobae.com/notas / 633727-Cromanon-la-Ciudad-mantendra-el-santuario-y-abrira-unacalle-paralela.html>. 
predio que lo circunda y que hacen del Espacio un verdadero museo. La memoria del Santuario, por su parte, tiene fronteras más débiles: fue construyéndose en plena calle, casi espontáneamente, y su edificación es bastante precaria. Hay allí una inscripción y una apropiación del espacio público que no opera de igual modo que en el Espacio.

Estos límites no atañen de un modo simplista a la materialidad del espacio físico en sí, puesto que todo espacio es siempre relacional; es decir, no existiría si no fuera por las asignaciones de sentido que los sujetos sociales depositan sobre él. ${ }^{14}$ Por lo tanto, estas fronteras se verifican en el plano de lo simbólico al intentar definir las memorias que encierran ambos lugares: qué es lo que se quiere recordar, qué es lo que habrá de ser olvidado. Sendos espacios se articulan a partir de una narrativa humanitaria (Markarian, 2004) a través de la cual se presenta a las víctimas -a partir de fotografías, datos personales, edad, etc.- de un modo tal que deja de lado los aspectos que se consideran más "inquietantes" o "contradictorios" de su identidad: los compromisos políticos controvertidos en el caso del Espacio para la Memoria y las prácticas culturales riesgosas en el Santuario Cromañón. Sin embargo consideramos que hay mayor estabilidad en el relato y menor disputa por las memorias de las víctimas en el primer caso que en el segundo. Tal vez en parte se deba a la diferencia temporal que separa a los hechos que se rememoran en ambos lugares, y que no sólo se refiere al tiempo de "institucionalización" de éstos como lugares de memoria, sino también al tiempo transcurrido desde la ocurrencia de los hechos que dichos lugares rememoran o conmemoran. El Santuario de Cromañón y la Plaza de la Memoria asociada a él se han convertido así en casos paradigmáticos de la construcción contradictoria del espacio público de la ciudad de Buenos Aires, ya que allí el poder y los sectores populares disputan por la apropiación de un mismo lugar y por la implantación de diferentes memorias y de diferentes formas de protesta, de conmemoración y de rememoración, mientras que el Espacio para la Memoria parece ya haber oficializado ciertas lecturas en torno a él y a las víctimas, más aún en cuanto que aquellos que definen las políticas públicas de memoria para el sitio han sido en muchos

${ }_{14}$ Rogerio Proença Leite hace una diferenciación fundamental entre espacio público y espacio urbano. Asocia el primero al concepto de "lugar" como "una determinada demarcación física y/o simbólica del espacio, cuyos usos lo califican y atribuyen sentidos diferenciados, orientando acciones sociales y siendo delimitado reflexivamente por éstas. Un lugar es siempre un espacio de representación, cuya singularidad es construida por la 'territorialidad subjetivada' (Guatarri, 1985) mediante prácticas sociales y usos semejantes” (Proença Leite, 2004: 284). 
Palacios y Rodríguez, ¿QUÉ MEMORIA(S) PARA BUENOS AIRES?

casos compañeros del grupo de edad y militancia de los detenidos y desaparecidos en la ESMA. El Espacio para la Memoria constituye así un ejemplo de lugar de memoria institucional (Delgado, 2007) o de memoria oficial, en el sentido que sugiere Nora (1984).

\section{Los diferentes recuerdos, los diferentes lugares, la misma ciudad}

Como manifiestan diversos autores (Delgado Ruiz, 1998; Amendola, 2000; Sassen, 2007), las ciudades van tomando un cariz cada vez más estético, en el sentido de que, a partir de la aplicación de estrategias de marketing, comienzan a ser remodeladas, "embellecidas", sobre todo a partir de la década de 1980 y como parte de un proceso de regeneración de áreas urbanas que ha ocurrido a escala mundial. Este proceso, unido a una nueva política urbanística cuya estrategia de ordenamiento y planificación de la ciudad se produce en términos monumentales y estetizantes (lo que Amendola define como "urbanismo escenográfico”) establece una narración sobre los lugares, eventos y grupos sociales que deben y pueden ser recordados por los habitantes de la ciudad.

Por otra parte, el modo de concebir el espacio público asociado a ideas de autonomía, diferenciado y diferenciable del resto de los ámbitos de la vida social, también ha sufrido ciertas modificaciones. Saskia Sassen (2007) advierte, por ejemplo, nuevas y diferentes formas de habitar este espacio común y menciona específicamente el ámbito de lo urbano: la experiencia es más fragmentada, porque también el tiempo y el espacio se viven en forma disruptiva, y la calle, lo público, aparece ya no como lugar colectivo, común, en donde se comparten vivencias, sino como algo amenazante. La consecuencia de ello es, como indica Bauman, que "un territorio despojado de espacio público brinda escasas oportunidades para debatir normas, confrontar valores, debatir y negociar" (Bauman, 1999: 37). En este marco nos resulta interesante confrontar los casos de estudio que aquí hemos analizado para preguntarnos de qué modo ambos lugares de memoria de la ciudad se presentan como verdaderos espacios públicos, esto es, abiertos, accesibles a todos, visibles y colectivos dentro del entramado urbano de Buenos Aires.

Como dijimos, el Espacio de la Memoria no supone ningún tipo de interrupción para quien circula por las calles de la ciudad. Sus imponentes dimensiones, su delimitación enrejada, sus edificios ya 
constituidos y a los cuales no se puede acceder sin concertación previa de la visita, hacen de la ex ESMA un lugar de memoria oficial. Por contraposición, el Santuario de Cromañón aparece como disruptivo: nos confronta con los imaginarios y las experiencias del duelo, de la negligencia, del crimen (al menos como problemas socialmente construidos), de la religiosidad popular, de la protesta social, de la apropiación de la calle, etc. En definitiva, las disputas por la(s) memoria(s) en el Espacio para la Memoria y en el Santuario de Cromañón y su Plaza asociada) reflejan controversias por el espacio público y por un proyecto de ciudad.

\section{Algunas consideraciones finales}

Para finalizar, y tomando en consideración lo expuesto hasta el momento, nos interesa preguntarnos por el futuro más o menos cercano de estos lugares de memoria que hemos analizado.

Como hemos visto, el Espacio para la Memoria constituye un lugar de reminiscencia oficial, acaso el más emblemático de la ciudad, cuya gestión y funcionamiento están guiados por políticas que se avalan e incluyen dentro de la órbita del Estado municipal y nacional. Sus fronteras físicas y simbólicas enmarcan al Espacio dentro de un predio delimitable, organizado conforme a ciertas funciones y al que se puede acceder por medio de la solicitud de una visita guiada. Si bien aún persisten diversas opiniones sobre el funcionamiento del ex centro clandestino, hay en términos generales cierto consenso que, por un lado, se manifiesta en la organización actual del Espacio (y como ejemplo, podemos citar la consigna de que "representar el horror genera parálisis”), y por otro, en el común rechazo, tácito o explícito, de ciertas opciones que se consideran poco pertinentes. Como observa Sarlo (2009),

no se debatió, ni siquiera en términos intelectuales exploratorios, que el predio de la ESMA presentara, en un futuro, una relación de un nuevo tipo entre las escuelas de formación de marinos militares y el museo que recordará los crímenes del terrorismo de Estado de los que son responsables las Fuerzas Armadas. Esa relación de nuevo tipo hubiera mostrado en el espacio la subordinación al orden democrático que la República debe establecer con las Fuerzas Armadas. Pero la ESMA, recuperada como bien público, fue, a la vez, restringida en ese mismo carácter [Sarlo, 2009: 503]. 
¿Será posible que este debate se presente dentro de unos años, o ya aparece como clausurado? ¿Podrá el Espacio seguir manteniendo sus usos actuales cuando se modifique el contexto político institucional mayoritariamente favorable que se ha presentado desde 2003 en relación con las políticas de memoria allí instauradas? ¿Corre el riesgo de transformarse en un museo de la memoria, adonde sólo sea posible asistir para observar lo que pasó, sin preguntarse por lo que pasa? ¿Acaso va camino a convertirse en un ícono turístico de la ciudad, como ocurre con el Museo del Holocausto en Berlín y Washington, por ejemplo? ¿Qué sucederá con cuestiones de índole más práctica, como la del financiamiento, la generación de recursos y el mantenimiento del predio? ¿Hasta cuándo podrá seguir funcionando como espacio de articulación?

Por otro lado, el caso del Santuario de Cromañón nos enfrenta con otro tipo de problemáticas y otras cuestiones para reflexionar. Apenas se había instalado, el gobierno local y varios sectores civiles manifestaban ya su preocupación por el corte de calles y por el futuro de dicha arteria, ya que el Santuario obligó a desviar el recorrido de una docena de líneas de colectivos que pasaban frente al microestadio y dejó permanentemente anulado el tránsito a pie por Mitre. Además, los vecinos de la zona reclamaron insistentemente que sus propiedades habían perdido valor por la cercanía del memorial y que la zona se había vuelto particularmente peligrosa, pues el Santuario de Cromañón servía como protección para delincuentes y chicos en situación de calle. También las empresas de colectivos ejercieron una fuerte presión para quitar el Santuario, dado que sufrían pérdidas económicas altísimas. En 2005 el gobierno de la ciudad intentó solucionar el problema reemplazando el Santuario de Cromañón por la Plaza de la Memoria, pero los esfuerzos en ese sentido no dieron resultado, ya que muchos padres del Movimiento por Cromañón se opusieron a desarmar el Santuario y así ambos monumentos convivieron. De allí en más, la administración municipal entabló repetidos diálogos con los reclamadores a fin de encontrar una solución para la zona que incluyera la remoción del Santuario, pese a lo cual la situación se mantuvo.

En agosto de 2009, habiendo finalizado el Juicio Penal del Tribunal Oral número 24 contra el gerente del local, la banda de rock que tocaba esa noche y los funcionarios públicos, entre otros ${ }^{15}$ la discusión

15 En la causa por estrago y cohecho se condenó al dueño del local a 20 años de prisión y se exculpó al grupo de rock casi en su totalidad. Al momento de escribir el presente artículo dicha sentencia está siendo apelada por los abogados de los deudos en los Tribunales de Casación, que aún no han expedido sentencia al respecto. 
acerca de reabrir la calle al tránsito se reanudó con más fuerza que nunca. Ese mismo año el gobierno de la ciudad llamó a licitación para llevar a cabo la realización de una plaza memorial en homenaje a las víctimas, cuyo diseño había ganado en 2005 el primer premio en el concurso "Memorial Cromañón" de la Sociedad Central de Arquitectos. El nuevo lugar incluye la reapertura de la calle cerrada y la eliminación del muro que separa dicha calle de la Plaza de la Memoria, la inclusión de rugosidad en el pavimento de Mitre y de Perón para obligar al tránsito a pasar lentamente y el cambio de nombre de Mitre entre Ecuador y Jean Jaurés por la denominación "Los Pibes de Cromañón”. En una segunda etapa se prevé la construcción de un museo en un túnel que pasará por debajo de las vías del ferrocarril Sarmiento y tendrá salida a la calle Perón. En definitiva, el nuevo espacio de rememoración de las víctimas de Cromañón incluye no sólo el lugar en donde sucedieron los hechos, sino también un espacio aledaño que nada tuvo que ver originalmente con la tragedia.

Pese a que el memorial cuenta con el beneplácito de varios grupos de familiares del Movimiento por Cromañón, algunos sectores se oponen y la zona sigue vallada. Estos padres sostienen que la calle misma sobre la que yacieron los cuerpos de las víctimas fatales es lugar santo y no se debe tocar. Como sostiene Sarlo (2009), la monumentalización del espacio público - en la forma del corte de calles- parece en este caso el único monumento suficiente a la memoria de las víctimas, no sólo por su exactitud en el señalamiento de los hechos que allí ocurrieron sino por su carácter activo en la tarea de permanecer señalando.

Pese a ello, la preadjudicación de la obra de la Plaza en Homenaje a las Víctimas de Cromañón por un valor de cuatro millones de pesos nos lleva a pensar que el futuro del Santuario de Cromañón como lugar de memoria se verá en duda. De esta manera, el proceso que va desde la instalación informal y espontánea del Santuario de Cromañón a la licitación y adjudicación institucional, económica, etc. del proyecto del nuevo museo por el gobierno de la ciudad, pasando por la construcción de la Plaza de la Memoria sobre terrenos del Estado Nacional cedidos por el ONABE, ${ }^{16}$ lleva a pensar un arco en cuanto a Cromañón como lugar de memoria, que va desde la informalidad y la territorialización de la memoria -ya que el Santuario de Cromañón está en el mismo espacio en el que sucedieron los hechos que éste señala, y surge del corazón mismo del incendio en tanto que se construye

${ }^{16}$ La sigla corresponde a Organismo Nacional de Administración de Bienes. 
Palacios y Rodríguez, ¿QUÉ MEMORIA(S) PARA BUENOS AIRES?

sobre la valla policial que los jueces de la causa penal ordenaron instalar para proteger las pruebas de esa noche e incluso está constituido por pertenencias de las víctimas- a la institucionalización y la reterritorialización de la memoria y de los lugares a ella asociados, pues el nuevo espacio de homenaje proyectado incluye la recuperación de la fachada del microestadio y la erección de una plaza y un museo en lugares que rodearon la zona del incendio pero que no tuvieron estrictamente que ver con él. ¿La institucionalización de Cromañón como lugar de reminiscencia seguirá acaso un recorrido similar al del Espacio para la Memoria? ¿Es posible pensar en este momento en políticas de rememoración que hagan del santuario un lugar de memoria oficial?

Si bien aún queda un largo camino por recorrer y los debates en torno a estos lugares se irán dando con el correr de los años y de los diversos contextos, pensamos que es posible y deseable seguir cuestionando el futuro de la(s) memoria(s) de una ciudad que no se resigna al olvido de sus víctimas.

\section{Bibliografía}

Amendola, Giandoménico (2000), La ciudad posmoderna. Magia y miedo de la metrópolis contemporánea, Madrid, Celeste Ediciones.

Bauman, Zygmunt (1999), La globalización, consecuencias humanas, Buenos Aires, FCE.

Delgado Ruiz, Manuel (1998), "Las estrategias de memoria y olvido en la construcción de la identidad urbana: el caso de Barcelona”, en D. Herrera Gómez (coord.), Ciudad y cultura. Memoria, identidad y comunicación, Antioquía, Ediciones Universidad de Antioquía, pp. 95-125.

Delgado, Manuel (2007), La ciudad mentirosa. Fraude y miseria del "modelo Barcelona", Madrid, Los libros de la Catarata.

Escolar, Cora (2000), Topografías de la investigación. Métodos, espacios y prácticas profesionales, Buenos Aires, Eudeba.

Feld, Claudia (2008), "ESMA hora cero: las noticias sobre la Escuela de Mecánica de la Armada en la prensa de la transición”, Sociohistórica: Cuadernos del CISH, vol. 23-24<http:/ / www.memoria.fahce.unlp.edu.ar/art_revistas / pr.4379/pr.4379.pdf>.

Jelin, Elizabeth (2002), Los trabajos de la memoria, Madrid, Siglo XXI / SSRC.

Jelin, Elizabeth (2004), "Los derechos humanos y la memoria de la violencia política y la represión: la construcción de un campo nuevo en las ciencias sociales", Estudios Sociales, vol. 14, núm. 27.

Jelin, Elizabeth y V. Langland (comps.) (2003), Monumentos, memoriales y marcas territoriales, Madrid, Siglo XXI. 
Lash, Scott (1993), Sociología del postmodernismo, Buenos Aires, Amorrortu.

Markarian, Vania (2004), "De la lógica revolucionaria a las razones humanitarias: Los exiliados uruguayos y las redes transnacionales de derechos humanos", Cuadernos del CLAEH, núm. 89, pp. 85-108.

Nora, Pierre (1984), "Entre memoria e historia. La problemática de los lugares", en Lieux de Mémoire I: La République, París, Gallimard (traducción al castellano en mimeo.).

Nora, Pierre (1998), "La aventura de Les lieux de mémoire", en Josefina Cuesta Bustillo (coord.), Memoria e historia, Madrid, Marcial Pons.

Palacios, Cecilia (2010), "El Espacio para la Memoria en Buenos Aires: un acercamiento en torno a algunas de las propuestas sobre su funcionamiento y gestión”, ponencia presentada en el Primer Encuentro Nacional Interdisciplinario de Derechos Humanos y Sociedad Civil; III Seminario Internacional de Derechos Humanos, Violencia y Pobreza, Montevideo, Facultad de Ciencias Sociales, Universidad de la República, 24 a 26 de noviembre.

Pollak, Michel (2006), "El testimonio", en Memoria, olvido, silencio. La producción social de identidades frente a situaciones limite, La Plata, Al Margen Editores.

Portal, María Ana (1999), "La multiculturalidad urbana en México o las diversas formas de apropiarse de la ciudad”, en R. Bayardo y M. Lacarrieu (comps.), La dinámica global / local. Cultura y comunicación: nuevos desafíos, Buenos Aires, Ediciones Ciccus La Crujía.

Proença Leite, Rogerio (2004), Contra-usos da cidade: lugares e espaço público na experiência urbana contemporánea, Campinas, Unicamp / UFS.

Rabotnikof, Nora (2007), "Memoria y política: el juego del tiempo en las transiciones", ponencia presentada en el Seminario de Estudios Avanzados "Izquierda, sociedad y democracia. ¿Hay un futuro democrático para América Latina?”, México, Instituto de Investigaciones Sociales, UNAM / Fundación Friedrich Ebert, $1^{\circ}$ de octubre.

Ramos, Ramón (1989), "Maurice Halbwachs y la memoria colectiva”, Revista de Occidente, núm. 100, pp. 63-81.

Reyes Mate, Manuel (2008), La herencia del olvido. Reflexiones en torno a la razón compasiva, Madrid, Errata Naturae.

Ricoeur, Paul (2002), "Definición de la memoria desde un punto de vista filosófico", en Academia Universal de las Culturas, ¿Por qué recordar?, Barcelona, Granica, pp. 24-28.

Sarlo, Beatriz (2009), "Vocación de memoria. Ciudad y museo", en Ricard Vinyes (coord.), El Estado y la memoria. Gobiernos y ciudadanos frente a los traumas de la historia, Barcelona, Nuevo Extremo, pp. 499-521.

Sassen, Saskia (2007), Una sociología de la globalización, Buenos Aires, Katz Editores.

Todorov, Tzvetan (2000), Los abusos de la memoria, Barcelona, Paidós Asterisco. Verón, Eliseo (1993) [1987], "Discursos sociales" en Eliseo Verón, La semiosis social. Fragmentos de una teoría de la discursividad, Barcelona, Gedisa, pp. 121-133. 
Palacios y Rodríguez, ¿QUÉ MEMORIA(S) PARA BUENOS AIRES?

\section{Acerca de las autoras}

Cecilia Palacios es licenciada en Ciencias de la Comunicación, maestra en Comunicación y Cultura y doctoranda en Ciencias Sociales, todo por la Facultad de Ciencias Sociales de la Universidad de Buenos Aires (UBA), Argentina. Es becaria doctoral del Consejo Nacional de Investigaciones Científicas y Técnicas (Conicet). Es integrante del proyecto UBACyT "Lugares y políticas de la memoria. Acontecimientos, saberes, testimonios e instituciones (1955-2010)", dirigido por Cora Escolar (Facultad de Filosofía y Letras, UBA), y es docente de la asignatura “Teorías y prácticas de la comunicación II", cátedra Carlos Mangone (Facultad de Ciencias Sociales, UBA).

Anabella Rodríguez es licenciada en Ciencias Antropológicas por la Facultad de Filosofía y Letras, Universidad de Buenos Aires (UBA); es doctoranda en Ciencias Sociales por la Facultad de Ciencias Sociales(UBA) y profesora adjunta en la Facultad de Derecho de la Universidad Nacional de Lomas de Zamora, Argentina. 
